\title{
MARÍ MOLLÀ, R. (2017). Facilitar las relaciones grupales y resolver los conflictos. Madrid: Editorial CCS.
}

DOI: 10.7203/anuari.psicologia.19.1.309

L'estudi de les interaccions interpersonals i l'anàlisi de resolució de conflictes ha sigut un tema molt analitzat des del punt de vista psicològic, per la qual cosa el lector podria preguntar-se: què podria aportar-me la lectura d'aquest llibre? Si bé destaca per ser una lectura d'enfocament pràctic i amé, el propi autor Ricard Marí ho presenta com un llibre que arreplega, en forma de reflexió personal, experiències $i$ dades que ha anat recopilant amb el temps, i que el tema central versa sobre l'enfocament de Carl Rogers en relació a la Psicologia Centrada en la Persona.

Quant al contingut de l'obra, cal mencionar que està escrita en la seua totalitat en castellà i que està formada per 259 pàgines de les quals 249 són de contingut teoricopràctic com a tal. A més, conté un pròleg de 4 pàgines que ajuden a aclarir la intencionalitat de l'autor amb la publicació i diferents metodologies usades per a la posada en pràctica de l'enfocament que pretén mostrar-nos. També es trobarà en l'índex de l'obra la referència un apartat de conclusions, amb la qual cosa l'autor pretén emfatitzar les actituds que mostren les persones, així com la responsabilitat social que ens uneix a un comportament en el marc de l'ètica. Convé assenyalar que el text es divideix en sis capítols, en els quals es desenrotllen cada un dels temes que es mencionaran a continuació així com una sèrie d'exercicis i exemples que l'autor introdueix en algun d'ells i que doten al capítol d'un enfocament més pràctic.

El primer dels apartats que m'agradaria ressaltar -per ser determinant en la introducció al lector en el context en què s'escriu l'obra- és el pròleg. Podria considerar-se este apartat de lectura obligatòria, ja que, al parer meu, l'autor expressa de forma breu el que pretén reflectir amb la redacció d'aquest llibre. A més, ens oferix una xicoteta descripció de cada un dels capítols que componen la seua obra.

Respecte al primer capítol, cal assenyalar que és un dels més importants ja que permetrà entendre al lector qüestions bàsiques per al posterior desenvolupament de la lectura. En ell es descriu de forma breu en què consisteix l'enfocament centrat en la persona. Aquesta visió sorgeix de mans de Carl Rogers, per la qual cosa aquest autor serà especialment rellevant en el desenvolupament del llibre. En aquest capítol se subscriu que el plantejament centrat en la persona no consisteix només en una tècnica pròpia de la psicoteràpia, sinó que es refereix a una forma determinada de veure la vida. Este últim aspecte junt amb 
l'enfocament pràctic que ens ofereix l'autor, pot ser determinant, per a atraure a lectors de qualsevol tipus i no exclusivament relacionats amb la branca de la Psicologia o ciències afins.

Quant al segon, ressalta els fonaments teoricocientífics que es realitzen des d'aquest punt de vista. En ell, s'exposa de manera argumentada les aportacions que realitza Rogers respecte a l'enfocament centrat en la persona, així se'ns presenta el marc teòric basant-se en el qual sorgeix. En definitiva, aquest capítol fa referència als fonaments teòrics que la sustenten. Això sí, cal destacar les nombroses reflexions que realitza l'autor per a induir el pensament crític del lector.

En el tercer capítol, trobem una gran mostra del que és la teoria de la personalitat i de la conducta, seguida de l'aportació de Rogers sobre aquesta teoria. Davall el meu punt de vista, a pesar de ser un dels capítols més llargs de l'obra, m'ha resultat una lectura molt àgil i dinàmica, on s'emfatitzen diferents aspectes de la personalitat que poden ser de curiositat per al lector que no estiga habituat a la lectura d'aquests temes.

Al quart capítol s'aprofundeix en les condicions de la relació interpersonal. És un dels capítols principals del llibre, ja que ens instrueix quant a com deuen ser les relacions interpersonals. A més, resulta molt interessant la incorporació d'exercicis per a reflexionar que inclou l'autor en forma de qüestionaris així com l'exemplificació de determinades conductes que poden donar-se en aquest tipus de relacions. També il·lustra uns casos determinats que ajuden a comprendre el lector el que l'autor ha anat explicant prèviament.

Pel que al cinqué capítol respecta, fa menció al recurs de les tècniques. En aquest capítol es classifiquen les diferents tècniques i s'aprofundeix en la tècnica del reflex. D'aquesta tècnica es mostren tant els tipus com diferents exemples, els quals ajuden a entendre com fer possible aquesta tècnica en cas de ser professionals de la teràpia, a més de ser, evidentment, un valuós recurs per als estudiants.

El sisé és l'últim dels capítols que ens presenta l'autor i en ell s'explica com crear un clima facilitador en els grups per a resoldre conflictes. Sense cap dubte, aquest pot ser un dels capítols més pràctics de tota l'obra. Gràcies a la seua utilitat pràctica, pot servir de referència tant per a professionals, com a estudiants així com per a qualsevol persona que al llarg del llibre s'haja vist cada vegada més i més involucrada i desitge dur a terme la proposta de l'autor, prou exemplificada per mitjà d'experiències i reflexions.

Finalment però igualment important, trobem l'apartat de conclusió. En ell, l'autor emfatitza el valor de la responsabilitat social per a aconseguir el comportament ètic i subratlla la capacitat que determinades actituds puguen servir com a mitjà per a tractar de comprendre altres perspectives i experiències alienes.

Per finalitzar, m'agradaria ressaltar la gran aportació que ha realitzat l'autor amb aquest llibre. A més d'ajudar a comprendre l'enfocament centrat en la 
persona de Carl Rogers, permet al lector fer-se una idea de com es pot aplicar aquesta perspectiva a una situació de teràpia $i$, no sols això, ja que estic convençuda de què moltes de les aportacions que apareixen en l'obra ajudarien a qualsevol persona a millorar en diferents aspectes de les relacions interpersonals que estableix dia a dia. En definitiva, el llibre ha de ser destacat no únicament per la seua gran aportació teòrica, sinó pel seu valor pràctic, estimulat principalment per les reflexions, exemples i experiències que l'autor ens mostra i que, sense cap dubte, podran enriquir les relacions dels lectors que tinguen el plaer de disfrutar d'aquest llibre.

\section{YASMINA EL ARBI CATALÁN Universitat de València}

Data de recepció: $11-07-2017$ Data d'acceptació: 02-10-2017 